\title{
MONEY AND PRODUCTION, AND LIQUIDITY TRAP
}

\author{
Pradeep Dubey and John Geanakoplos
}

May 8, 2006

\begin{abstract}
We prove the existence of monetary equilibrium in a finite horizon economy with production. We also show that if agents expect the monetary authority to significantly decrease the supply of bank money available for short term loans in the future, then the economy will fall into a liquidity trap today.
\end{abstract}

\section{Introduction}

Jean-Michel Grandmont combined a deep interest in monetary theory with a total mastery of the techniques of Walrasian general equilibrium theory. In his famous monograph, Money and Value, he began by asking whether monetary equilibrium (entailing a positive value for fiat money) would always exist if prices were flexible. He ended his book by asking whether the central bank would necessarily put the economy into a liquidity trap if it tried to force the nominal rate of interest down to zero.

In this paper we investigate exactly these two questions. We propose a different kind of monetary model, based on rational expectations equilibrium instead of the temporary equilibrium envisaged by Grandmont, and we work with a different definition of liquidity trap. As a result we reach different conclusions. In our model, monetary equilibrium always exists. On the other hand, we show that the liquidity trap springs shut when the public comes to believe that the supply of bank money will grow too slowly. For example, if the central bank increases the supply of money for short term loans today but is expected to restore the normal supply in the future, the public will be anticipating a decrease in the supply of money which, if sufficiently extreme, will inevitably render further monetary injections today powerless.

We introduce a two-period general equilibrium model with households and producers and an incomplete set of financial assets called derivatives. Production plays a central role in giving money value in our model because the only way for the firms to distribute profits to their shareholders is by selling their goods for money and then paying the revenue out as dividends. We also assume that firms have endowments of goods, so that they are bound to be selling something valuable for money. 
We introduce a monetary authority that can give loans of varying maturities. This money is called inside money by Grandmont in Money and Value. In addition, agents have private endowments of money called outside money.

We show that under very mild concavity assumptions, monetary equilibrium must always exist, no matter what the stocks of central bank money $M_{0}, M_{\overline{0}}, M_{1}$ put up for short loans at period 0 , long loans at period 0 , and short loans at period 1 . By contrast, Grandmont found that equilibrium existed only for a narrow range of money stocks, depending on the elasticity of expectations.

We proved a similar universal existence theorem for pure exchange economies with incomplete markets and rational expectations in [2003b]. But there it was necessary that the ratio of outside money to inside money be no higher than the gains to trade at the initial endowment point. In our current model no assumption need be made about gains to trade, because the sales by the firms of goods will give money value.

Lucas [1980], and Lucas-Stokey [1987] studied equilibrium for economies in which every agent was forced to sell his endowments (to himself). But those papers were set in an infinite horizon economy. We are able to prove the existence of equilibrium in a finite horizon economy, in which only the firms are obliged to sell goods for money. Needless to say, finite horizon economies are computationally more tractable than infinite horizon economies.

As for the liquidity trap, Grandmont showed quite generally in his model that as the monetary authority drove the interest rate to zero in the first period it would necessarily be led to increase the stock of bank money ( $M_{0}$ in our model) to infinity. We reach the opposite conclusion. We show that if the central bank increases $M_{0}$, but agents all assume that it will not increase future stocks of bank money $M_{1}$ (or long term loans $M_{\overline{0}}$ ), then the interest rate $r_{0}$ will necessarily hit zero while $M_{0}$ is still finite. Further increases in $M_{0}$ will induce agents to hold larger and larger real balances in their portfolios, as they borrow the money and hoard it, returning it unspent at the end of the loan. Tobin [1980] defined the liquidity trap as the accumulation of ever larger stocks of real money balances in private portfolios, and that is what necessarily occurs in our model.

If, on the other hand, the bank could commit to increasing all the loans $M_{0}, M_{\overline{0}}, M_{1}$ in the same proportion, then all interest rates would gradually be driven toward zero as the bank money inexorably increased toward infinity. But then prices would also increase toward infinity, and the holdings of real money balances would stay bounded.

Krugman [1998] proposed a similar explanation for the liquidity trap, based on expectations of insufficient future money growth. His model consisted of an infinite horizon, single commodity, single agent economy, and the liquidity trap arose when the expected rate of money growth became less than the real rate of interest. In an economy with multiple goods, there is no well-defined real rate of interest. Nevertheless, our liquidity trap theorem can be taken to be the natural extension of Krugman's idea to more general economies. We also developed the same theory of the liquidity trap in a pure exchange economy in [2006]. The liquidity trap becomes a more serious welfare problem when there is production.

We describe the model in Section 2, and state the Equilibrium Existence Theorem 
in Section 3. In Section 4 we state and prove the Liquidity Trap Theorem. In Section 5 we comment on our assumption that the goals of each firm can be represented by a utility function depending on all the macro variables and, in a concave way, on the choices of the firm. One special case is when each firm has a single owner who is not allowed to default on firm promises (bonds and bank loans). By exploiting the dependence of the utility on the macro variables we show that the model can also encompass various cases with multiple owners and firm default. The paper concludes with an appendix containing the proof of the Equilibrium Existence Theorem.

\section{The Monetary Economy}

\subsection{The Underlying Economy}

The set of states of nature is $S^{*}=\{0,1, \ldots, S\}$. State 0 occurs in period 0 , and then nature moves and selects one of the states in $S=\{1, \ldots, S\}$ which occur in period 1.

The set ${ }^{1}$ of commodities is $L=\{1, \ldots, L\}$. Thus the commodity space may be viewed as $\mathbb{R}_{+}^{S^{*} \times L}$. The pair $s \ell$ denotes commodity $\ell$ in state $s$.

The set of households is $H=\{1, \ldots, H\}$. Household $h$ has initial endowment $e^{h} \in \mathbb{R}_{+}^{S^{*} \times L}$ and utility function $u^{h}: \mathbb{R}_{+}^{S^{*} \times L} \rightarrow \mathbb{R}$. We assume that no household has the null endowment of commodities in any state, i.e., for $s \in S^{*}$ and $h \in H$ :

$$
e^{h}=\left(e_{s 1}^{h}, \ldots, e_{s L}^{h}\right) \neq 0
$$

and each commodity is present in the aggregate:

$$
\sum_{h \in H} e^{h} \gg 0
$$

We further assume that each $u^{h}$ is concave and smooth, and

$$
\frac{\partial u^{h}}{\partial x_{s \ell}}>0 \text { for all } h \in H, s \in S^{*}, \ell \in L
$$

The set of firms is $J=\{1, \ldots, J\}$. Each firm $j$ has a production set $Y^{j} \subset \mathbb{R}_{+}^{L} \times$ $\mathbb{R}_{+}^{L \times S}$, where $\left(x_{0}, \bar{y}\right) \in \mathbb{R}_{+}^{L} \times \mathbb{R}_{+}^{L \times S}$ specifies inputs $x_{0}$ in period 0 and outputs $\bar{y}_{s} \in \mathbb{R}_{+}^{L}$ in each state $s$ in period 1. Note that there are no outputs in period 0; production, in our model, takes time. We impose the standard restrictions

(i) $Y^{j}$ is convex and closed

(ii) $0 \in Y^{j}$

(iii) For any $A>0$, there exists $B>0$ such that if $\left(x_{0}, \bar{y}\right) \in Y^{j}$, and $\left\|x_{0}\right\| \leq A$, then $\|y\|<B$, where \|\| denotes the max norm.

\footnotetext{
${ }^{1}$ For $X=\{1, \ldots, x, \ldots, X\}$ it will be clear from the context whether $X$ refers to the set or to its last element.
} 
Firm $j$, in addition, has endowments $e^{j} \in \mathbb{R}_{+}^{L \times S}$, with $e_{s}^{j} \equiv\left(e_{s 1}^{j}, \ldots, e_{s L}^{j}\right) \neq 0$ for each $s \in S$. This completes the description of the physical structure of the firm. ${ }^{2}$

\subsection{Money}

Money plays a crucial role in the economy because we assume that it is the sole medium of exchange and hence all purchases are out of cash (the so-called Clower cash-in-advance constraint).

Money is fiat and enters the economy in two ways. Each agent $t \in H \cup J$ has endowments of money $m_{s}^{t} \geq 0$ in each state $s \in S^{*}$, with $\sum_{h \in H} m_{0}^{h}>0$ and $\sum_{j \in J} m_{0}^{j}=0$. We call this outside money. There is also a central bank that stands ready to make short loans totalling $M_{s}>0$ dollars for one period in each state $s \in S^{*}$ and also to make long loans totalling $M_{\overline{0}}>0$ for two periods starting at date 0 . Unlike the commodities, money is perfectly durable.

Agents borrow money from the bank by promising to pay back the loan with interest. If the interest rate on loan $n \in N \equiv\{\overline{0}, 0,1, \ldots, S\}$ is $r_{n}$, then anyone can borrow $\mu_{n} /\left(1+r_{n}\right)$ dollars by promising to repay $\mu_{n}$ dollars at the time the loan comes due.

\subsection{Fundamental Macro Variables}

The fundamental macro variables are

$$
\bar{\eta}=(r, \rho, p, \bar{\delta}, \Delta, W, V)
$$

where

$$
\begin{aligned}
& r \in \mathbb{R}_{+}^{N \cup J} \equiv \quad \text { interest rates on bank loans } n \in N \equiv\{\overline{0}, 0,1, \ldots, S\} \text { and } \\
& \text { firm bonds } j \in J \\
& \rho \in \mathbb{R}_{++}^{J} \equiv \quad \text { prices of shares of the } J \text { firms } \\
& p \in \mathbb{R}_{++}^{S^{*} L} \equiv \quad \text { commodity prices } \\
& \bar{\delta}, \Delta \in \mathbb{R}_{+}^{H J} \equiv \quad \text { initial, final shares held by households } h \in H \text { of firm } j \in J \\
& W \in \mathbb{R}_{+}^{S J} \equiv \quad \text { payoffs in states } s \in S \text { of firm bonds } j \in J \\
& V \in \mathbb{R}_{+}^{S J} \equiv \quad \text { dividend payoffs per share of firms } j \in J \text { in states } s \in S
\end{aligned}
$$

Sometimes we write

$$
\bar{\eta}=\left(\bar{\eta}_{0},\left(\bar{\eta}_{s}\right)_{s \in S}\right)=\left(\left(r_{0}, r_{\overline{0}},\left(r_{j}\right)_{j \in J}, \rho, p_{0}, \bar{\delta}, \Delta\right),\left(r_{s}, p_{s}, W_{s}, V_{s}\right)_{s \in S}\right)
$$

breaking $\bar{\eta}$ into its state components.

\footnotetext{
${ }^{2}$ For simplicity of notation we assume that the firm has no endowment of goods (or money) in period zero, though this could be easily included. Thus we have the inputs of the firm in period zero precisely equal to its purchases of commodities, and no bank deposits by firms.
} 


\subsection{Financial Structure of the Firm}

There are initial shareholders; $\bar{\delta}_{j}^{h}$ denotes the shares of firm $j$ held by agent $h$ (we normalize the total initial shares in each firm to be 1 , so $\sum_{h=1}^{H} \bar{\delta}_{j}^{h}=1$ ). The firm can issue $f^{j}$ new shares, diluting the original shareholdings to a fraction $1 /\left(1+f^{j}\right)$. Let the price of the firm's share be $\rho_{j}$. Then $\rho_{j} f^{j}$ is the money raised by the new issue.

Two other sources of finance are available. The firm can issue bonds $\beta^{j}$, as well as borrow money $\mu_{\overline{0}}^{j} /\left(1+r_{\overline{0}}\right)$ from the bank. (Since production takes time, there is no point in the firm borrowing on the short loan markets; and, since $m_{0}^{j}=0$, the firm has no money to lend). A bond of firm $j$ is a promise by $j$ to deliver one dollar in every state $s=1, \ldots, S$ in period 1 . If its bond price is assumed positive we can write it as $1 /\left(1+r_{j}\right)$ where $r_{j}$ is the implicit interest promised by the bond. The firm thus raises in total $\rho_{j} f^{j}+\mu_{\overline{0}}^{j} /\left(1+r_{\overline{0}}\right)+\beta^{j} /\left(1+r_{j}\right)$ from the "capital markets" (shares, bank, bonds). Hence $\left[\mu_{\overline{0}}^{j} /\left(1+r_{\overline{0}}\right)+\beta^{j} /\left(1+r_{j}\right)\right] / \rho_{j}\left(1+f^{j}\right)$ is the "debt-equity" ratio of firm $j$.

We wish to imagine perfectly competitive firms. We shall therefore suppose the firms treat their own prices $\rho_{j}$ as fixed when they raise money on capital markets. Since $\rho_{j}$ is influenced by the willingness of households to buy shares in the firm, which in turn depends on their expectations about firm bond payments and dividends, we also fix those expectations $W_{s j}$ and $V_{s j}$, like $\rho_{j}$, as part of the macro variables. The firm is, however, choosing how much to issue, and its dividends, itself. In equilibrium these choices will match the expectations.

Is it reasonable for households to assume that $\rho_{j}, W_{s j}$ and $V_{s j}$ are fixed when the firm issues more shares? We say yes, if the new issue size is infinitesimal compared to the scale of the firm. The household thinks that the new money will be used by the firm to produce the same returns as the old equity (or bond) was yielding.

A concrete way of interpreting our assumption of fixed $\rho_{j}, W_{s j}$, and $V_{s j}$ is that the firm is really the sum of a continuum of small "divisions." Each division can issue its own shares, but they get pooled with the shares of the other divisions, giving any shareholder equal ownership of all the divisions, in proportion to the fraction of all shares he bought. General Electric, for example, includes a dishwasher division, an engine division, a financial services division, and so on. When the firm issues shares to raise money for one division, it sells ownership of all its divisions.

In short, the firm chooses $\sigma^{j} \equiv\left(f^{j}, \mu_{\overline{0}}^{j}, \beta^{j}, y^{j}\right) \geq 0$ satisfying

$$
p_{0} \cdot x_{0}^{j} \leq \rho_{j} f^{j}+\frac{1}{1+r_{\overline{0}}} \mu_{\overline{0}}^{j}+\frac{1}{1+r_{j}} \beta^{j} \text { and }\left(x_{0}^{j}, \bar{y}^{j}\right) \equiv y^{j} \in Y^{j}
$$

i.e., that its purchase of inputs be financed out of the money on hand, and that production be feasible. The set of all such $\sigma^{j}$ is denoted by $\Sigma_{\bar{\eta}}^{j}$.

The dividend paid to each share of firm $j$ in state $s \in S$ is

$$
v_{s j}=v_{s j}\left(\bar{\eta}, \sigma^{j}\right)=\left(\left(p_{s} \cdot\left(\bar{y}_{s}^{j}+e_{s}^{j}\right)-\mu_{\overline{0}}^{j}\right)^{+}-\beta^{j}\right)^{+} /\left(1+f^{j}\right)
$$


where $c^{+}=\max \{0, c\}$ for any real number $c$. This is so because the firm is required to first repay $\mu_{\overline{0}}^{j}$ to the bank. Then, if it has money left, $\beta^{j}$ is paid to the bondholders. ${ }^{3}$ Each bond of firm $j$ thus pays

$$
w_{s j}=w_{s j}\left(\bar{\eta}, \sigma^{j}\right)=\min \left\{\frac{1}{\beta^{j}}\left[p_{s} \cdot\left(\bar{y}_{s}^{j}+e_{s}^{j}\right)-\mu_{\overline{0}}^{j}\right]^{+}, 1\right\} .
$$

in state $s \in S$, if $\beta^{j}>0$. What remains, after all creditors have been reimbursed, is finally passed on to the shareholders.

Note that bondholders and shareholders are not held liable for the bankruptcy of the firm when it is unable to repay the bank. Shareholders, in addition, are not liable for the bondruptcy incurred by the firm when it cannot payoff its bonds. This is in keeping with the "limited liability clause" for corporations.

We could have required some ("unincorporated" small business) firms to have unlimited liability, i.e., to pass along all their debts to their shareholders, who would then be obligated to pay or else face penalties. This would leave intact all our results on the existence of monetary equilibrium and the liquidity trap.

\subsection{Derivatives}

In modern economies, agents can trade derivative assets, as well as the old-fashioned stocks and bonds. Derivatives have payoffs that depend on the fundamental macro variables. For example, a call option on firm $j$, with strike price $\lambda_{j}$, pays off $\max \left(V_{s j}-\right.$ $\left.\lambda_{j}, 0\right)$ in each state $s \in S$. The strike price $\lambda_{j} \in \mathbb{R}$ is usually chosen with the current or past fundamental macro variables in mind. One natural choice is to set $\lambda_{j}=\rho_{j}$, or (say) $.9 \rho_{j}$. Another example of a derivative asset is an inflation-indexed promise, which delivers $p_{s} \cdot \Lambda_{s}$ in state $s \in S$, where $\Lambda_{s} \in \mathbb{R}_{+}^{L}$ is a fixed basket of goods.

Thus we suppose that derivative $k \in K \equiv\{1, \ldots K\}$ promises payoffs

$$
A_{s k}\left(\bar{\eta}_{0}, \bar{\eta}_{s}\right)
$$

dollars in each state $s \in S$, where each $A_{s k}$ varies continuously with $\bar{\eta}_{0}$ and $\bar{\eta}_{s}$. Any household $h \in H$ is free to buy or sell arbitrary amounts of derivative $k$ at the price $\pi_{k} \cdot{ }^{4}$ Since there are no a priori endowments of derivatives, such sales are called "short sales."

We encompass many derivatives in our model. But we need one assumption to make sure equilibrium exists. Let the set of fundamental macro variables on which there is no obvious capital market arbitrage be given by

$$
\Omega=\left\{\bar{\eta}: \rho \gg 0, p \gg 0, r_{\overline{0}} \geq 0 \text { and } \frac{1}{1+r_{\overline{0}}} \min _{s \in S} V_{s j} \leq \rho_{j} \leq \max _{s \in S} V_{s j}\right\} .
$$

\footnotetext{
${ }^{3}$ We could interchange this order without affecting our results, i.e., firms pay out bondholders first, and then the bank. What is important is that the total debt must be cleared before profits can be distributed as dividends to the shareholders.

${ }^{4}$ For simplicity, we keep each firms out of the derivative asset markets and the capital markets of other firms.
} 
We make a derivative delivery hypothesis (DDH): there is a number $\gamma>0$ such that, for every derivative $k \in K$ and $\bar{\eta} \in \Omega$, there is a state $s \in S$ with

$$
A_{s k}\left(\bar{\eta}_{0}, \bar{\eta}_{s}\right) \geq \gamma \min _{j \in J, \ell \in L}\left\{\rho_{j}, p_{s \ell}\right\}
$$

Thus we assume that the economy will not bother to trade a derivative which, given $\bar{\eta} \in \Omega$, will be close to worthless in every state. Our formalism includes many call and put options on firm shares, as well as inflation indexed promises. For example, a call option with strike price equal to $90 \%$ of today's stock price $\rho_{j}$ will, for any $\bar{\eta} \in \Omega$, pay off at least $.10 \rho_{j}$ in some state $s$. Similarly a promise to deliver a nonzero vector of real goods $\Lambda \in \mathbb{R}_{+}^{S L} \backslash\{0\}$ also trivially satisfies our assumption.

\subsection{Macro Variables}

If we add the prices $\pi=\left(\pi_{1}, \ldots, \pi_{K}\right)$ of derivatives to the fundamental macro variables, we get the (full) macro variables

$$
\eta=(r, \rho, \pi, p, \bar{\delta}, \Delta, W, V)
$$

\subsection{Payoff of the Firm}

When markets are incomplete, there are competing views ${ }^{5}$ of how the firm behaves. We wish to adopt a formalism which will accommodate many of them. To this end we postulate a payoff function $u^{j}\left(\eta, \sigma^{j}\right)$ for firm $j$ such that $u^{j}\left(\eta, \sigma^{j}\right)$ is continuous (in all its variables), and concave in $\sigma^{j} \in \Sigma_{\eta}^{j}$ for any fixed $\eta$.

The function $u^{j}$ cannot be arbitrary if equilibrium is to exist. We have not placed any limits on firm borrowing, for example. If the manager were only interested in getting the firm to purchase $x_{0 \ell}$ (perhaps his relatives' labor) he could borrow money endlessly and buy endlessly, perhaps defaulting on the bonds. This would ultimately destroy the bank or bond loan market, not to mention the labor market, and thus destroy the existence of equilibrium. Such behavior would of course be contrary to the desires of the shareholders, who by assumption cannot pull any resources out of the firm except as dividends $v_{s j}$ paid out in the last period. If the bank and bond holders are not repaid, the dividends must be zero.

We could restore equilibrium by imagining that the manager suffers a penalty if the firm defaults. Indeed, we shall later take this as one special case. But it turns out that equilibrium exists under much weaker hypotheses. It suffices that $u^{j}$ should reflect the interests of its shareholders, at least to some extent. With this in mind, we introduce the shareholder control hypothesis ( $\mathrm{SCH})$ :

$$
u^{j}\left(\eta, \sigma^{j}\right)<u^{j}(\eta, 0)
$$

whenever

$$
v_{s j}\left(\eta, \sigma^{j}\right)<p_{s} \cdot e_{s}^{j} \equiv v_{s j}(\eta, 0) \text { for every } s=1, \ldots, S .
$$

\footnotetext{
${ }^{5}$ See Section 5.
} 
Otherwise the firm could choose $\sigma^{j}=0$ (i.e., $y^{j}=0$ and $f^{j}=\beta^{j}=\mu_{\overline{0}}^{j}=0$ ) and improve the dividend on its share in every state. Our hypothesis thus embodies the idea that the shareholders have enough control of the firm to maintain at least this weak form of optimality for themselves.

This will be enough to ensure that equilibrium exists and that the bank loans and bonds pay something of value. In fact they will be fully redeemed in at least one state. Their prices will adjust to compensate for defaults, if defaults occur in the other states, so as to maintain market clearing at the issuance date.

\subsection{Liquidity Constraints for the Households}

The sequence of events, in our monetary economy, is as follows. There are two time periods. In period zero agents borrow fixed stocks of money $M_{0}, M_{\overline{0}}$ from the bank at interest rates $r_{0}, r_{\overline{0}}$ respectively; agents may also deposit money, that is, loan at the same interest rates $r_{0}$ or $r_{\overline{0}}$. Next the capital markets meet (for the trade of shares, bonds, and derivatives) followed by commodity markets. After this there is a move of chance and we enter one of the states $s=1, \ldots, S$ in period one. During this time firms complete production. (Note that inputs in period 0 yield outputs in period 1.) In any state $s \in S$ there is a fresh dispersal of bank money $M_{s}$ at interest rate $r_{s}$, followed by another round of trade in commodities. ${ }^{6}$ Then all deliveries take place simultaneously: households deliver on their derivatives and firms repay the bank, the bondholders and the shareholders in that order of seniority (as discussed earlier). Finally agents settle their debts with the bank.

In our model every transaction that an agent undertakes requires the physical transfer of money out of what he has on hand at the time. This amounts to what we have called the liquidity constraint. The upshot is that we have a well defined physical process in which effect follows cause in a time sequence. By contrast, general equilibrium analysis steers clear of liquidity constraints because all transactions are imagined to occur simultaneously. The point of our paper is to go beyond this and to analyze the effects of liquidity constraints, when defaults and bankruptcies are permitted to occur.

For any fixed choice of macrovariables $\eta$, we now describe the set $\Sigma_{\eta}^{h}$ of feasible choices of $h \in H$, as well as the outcome that accrues to $h$ as a function of $\eta$ and of his choice $\sigma^{h} \in \Sigma_{\eta}^{h}$.

First denote

$\mu_{n}^{h} \equiv$ bank bonds $n \in N$ sold by $h$

$f_{j}^{h} \equiv$ shares of firm $j \in J$ sold by $h$

$\alpha_{k}^{h} \equiv$ derivatives $k \in K$ sold by $h \in H$

$q_{s \ell}^{h} \equiv$ commodity $\ell \in L$ sold by $t \in H \cup J$ in state $s \in S^{*}$

Also, a tilda on any variable will denote money spent on it. Thus $\tilde{\mu}_{n}^{h} \equiv$ money deposited (i.e. money spent on bank bonds of type $n$ ) by $h, \tilde{f}_{j}^{h} \equiv$ money spent by

\footnotetext{
${ }^{6}$ To fix ideas we have chosen a particular sequence of events, but this can be permuted quite freely without affecting any of our qualitative results. For instancee, the loan on $M_{\overline{0}}$ could come due before the move of chance, or after the conclusion of trade in commodities in period one, or even later.
} 
$h \in H$ on shares of firm $j \in J, \tilde{\beta}_{j}^{h} \equiv$ money spent by $h$ on bond $j \in J, \tilde{\alpha}_{k}^{h} \equiv$ money spent by $h$ on derivative $k, \tilde{q}_{s \ell}^{h} \equiv$ money spent by $h$ on $\ell \in L$ in state $s \in S^{*}$, etc.

The choice $\sigma^{h} \equiv\left(\left(\mu_{n}^{h}, \tilde{\mu}_{n}^{h}\right)_{n \in N},\left(f_{j}^{h}, \tilde{f}_{j}^{h}, \tilde{\beta}_{j}^{h}\right)_{j \in J},\left(\alpha_{k}^{h}, \tilde{\alpha}_{k}^{h}\right)_{k \in K},\left(q_{s \ell}^{h}, \tilde{q}_{s \ell}^{h}\right)_{s \in S^{*}, \ell \in L}\right) \geq 0$ must satisfy $f_{j}^{h} \leq \bar{\delta}_{j}^{h}$ for $j \in J$ and $q_{s \ell}^{h} \leq e_{s \ell}^{h}$ for $s \ell \in S^{*} L$; as well as the following liquidity constraints (where $\Delta(\nu) \equiv$ difference between RHS and LHS of inequality $\nu)$ :

(1) Bank deposits in period $0 \leq$ money endowed

$$
\tilde{\mu}_{0}^{h}+\tilde{\mu}_{\overline{0}}^{h} \leq m_{0}^{h} .
$$

(2) Expenditures on shares, bonds, derivatives $\leq$ money left in $(1)+$ money borrowed

$$
\sum_{j \in J} \tilde{f}_{j}^{h}+\sum_{j \in J} \tilde{\beta}_{j}^{h}+\sum_{k \in K} \tilde{\alpha}_{k}^{h} \leq \Delta(1)+\frac{\mu_{0}^{h}}{1+r_{0}}+\frac{\mu_{\overline{0}}^{h}}{1+r_{\overline{0}}} .
$$

(3) Expenditures on commodities $\leq$ money left in $(2)+$ money obtained from sales of stocks and derivatives

$$
\sum_{\ell \in L} \tilde{q}_{0 \ell}^{h} \leq \Delta(2)+\sum_{j \in J} \rho_{j} f_{j}^{h}+\sum_{k \in K} \pi_{k} \alpha_{k}^{h}
$$

(4) Money owed and repaid on loan $0 \leq$ money left in $(3)+$ money from commodity sales

$$
\mu_{0}^{h} \leq \Delta(3)+\sum_{\ell \in L} p_{0 \ell} q_{0 \ell}^{h}
$$

Furthermore, in each state $s \in S$ in period 1, we must have

$(5)_{s}$ Money deposited on loan $s \leq$ money inventoried from period $0+$ money endowed

$$
\tilde{\mu}_{s}^{h} \leq \Delta(4)+m_{s}^{h}
$$

$(6)_{s}$ Expenditures on commodities $\leq$ money left in $(5)_{s}+$ money borrowed on bank loan $s$

$$
\sum_{\ell \in L} \tilde{q}_{s \ell}^{h} \leq \Delta(5)_{s}+\frac{\mu_{s}^{h}}{1+r_{s}} .
$$

$(7)_{s}$ Money delivered on derivatives $\leq$ money left in $(6)_{s}+$ money obtained from commodity sales:

$$
\sum_{k \in K} A_{s k}\left(\bar{\eta}_{0}, \bar{\eta}_{s}\right) \alpha_{k}^{h} \leq \Delta(6)_{s}+\sum_{\ell \in L} p_{s \ell} q_{s \ell}^{h} .
$$

$(8)_{s}$ Money owed and repaid on loan 0 and loan $\overline{0} \leq$ money left in $(7)_{s}+$ money obtained from stock dividends, bond deliveries, and derivative deliveries

$$
\mu_{0}^{h}+\mu_{0}^{h} \leq \Delta(7)_{s}+\sum_{j \in J} \delta_{j}^{h} V_{s j}+\sum_{j \in J} W_{s j} \frac{\tilde{\beta}_{j}^{h}}{\left(1+r_{j}\right)}+\sum_{k \in K} A_{s k}\left(\bar{\eta}_{0}, \bar{\eta}_{s}\right) \frac{\tilde{\alpha}_{k}^{h}}{\pi_{k}},
$$


where

$$
\delta_{j}^{h}=\frac{\tilde{f}_{j}^{h}}{\rho_{j}}+\left(\bar{\delta}_{j}^{h}-f_{j}^{h}\right) .
$$

These constraints define the feasible set $\sum_{\eta}^{h}$. Since the macrovariables $\eta$ are viewed as fixed (unaffected by $\sigma^{h}$ ) and all the inequalities are linear in $\sigma^{h}$, we see that $\Sigma_{\eta}^{h}$ is convex.

The consumption that accrues to $h \in H$ on account of $\sigma^{h} \in \Sigma_{\eta}^{h}$ and $\eta$ is $x^{h}$, where:

$$
x_{s \ell}^{h}=x_{s \ell}^{h}\left(\eta, \sigma^{h}\right)=e_{s \ell}^{h}-q_{s \ell}^{h}+\frac{\tilde{q}_{s \ell}^{h}}{p_{s \ell}}
$$

for all $s \ell \in S^{*} L$; and it yields utility $u^{h}\left(x^{h}\right)$ to $h$.

\section{Monetary Equilibrium}

We say that $\left\langle\eta,\left(\sigma^{t}\right)_{t \in H \cup J}\right\rangle$ constitutes a monetary-equilibrium (ME) for the monetary economy $E=\left\langle\left(u^{h}, e^{h}, m^{h}\right)_{h \in H},\left(u^{j}, e^{j}, m^{j}, Y^{j}\right)_{j \in J}, A,\left(M_{0}, M_{\overline{0}},\left(M_{s}\right)_{s \in S}\right)\right\rangle$ if

(i) All agents maximize, i.e.,

$$
\sigma^{h} \in \underset{\tilde{\sigma}^{h} \in \Sigma_{\eta}^{h}}{\arg \max }\left(u^{h}\left(x^{h}\left(\eta, \tilde{\sigma}^{h}\right)\right), \text { for } h \in H\right.
$$

and

$$
\sigma^{j} \in \underset{\tilde{\sigma}^{j} \in \Sigma_{\bar{\eta}}^{j}}{\arg \max }\left(u^{j}\left(\eta, \tilde{\sigma}^{j}\right)\right), \text { for } j \in J
$$

(ii) All markets clear

(a) Loans $(n \in N)$

$$
\frac{1}{1+r_{n}} \sum_{t \in H \cup J} \mu_{n}^{t}=M_{n}+\sum_{h \in H} \tilde{\mu}_{n}^{h}
$$

(where, recall, $\mu_{n}^{j} \equiv 0$ if $j \in J$ and $n \in N \backslash\{\overline{0}\}$ ).

(b) Shares $(j \in J)$

$$
\rho_{j}\left(f^{j}+\sum_{h \in H} f_{j}^{h}\right)=\sum_{h \in H} \tilde{f}_{j}^{h}
$$

(c) Bonds $(j \in J)$

$$
\frac{1}{1+r_{j}} \beta^{j}=\sum_{h \in H} \tilde{\beta}_{j}^{h}
$$

(d) Derivatives $(k \in K)$

$$
\pi_{k} \sum_{h \in H} \alpha_{k}^{h}=\sum_{h \in H} \tilde{\alpha}_{k}^{h}
$$


(e) Commodities $\left(s \ell \in S^{*} L\right)$

$$
p_{s \ell} \sum_{t \in H \cup J} q_{s \ell}^{t}=\sum_{t \in H \cup J} \tilde{q}_{s \ell}^{t}
$$

(where, recall, $q_{0 \ell}^{j}=0$, and $\tilde{q}_{s \ell}^{j}=0$ and $q_{s \ell}^{j}=e_{s \ell}^{j}+\bar{y}_{s \ell}^{j}$ for all $\ell \in L, s \in$ $S, j \in J)$

(iii) Expectations of final share-holdings, and of the value of the firm and its bonds are fulfilled: $(\forall h \epsilon H, j \epsilon J, s \epsilon S)$ :

(a) $\Delta_{j}^{h}=\delta_{j}^{h}=\bar{\delta}_{j}^{h}-f_{j}^{h}+\left(\tilde{f}_{j}^{h} / \rho_{j}\right)$

(b) $W_{s j}= \begin{cases}w_{s j}\left(\eta, \sigma^{j}\right), & \text { if } \beta_{j}>0 \\ \text { arbitrary except that } W_{s j}=1 \text { if } V_{s j}>0, & \text { if } \beta_{j}=0\end{cases}$

(c) $V_{s j}=v_{s j}\left(\eta, \sigma^{j}\right)$

Note that in keeping with rational expectations, the expected payoffs $W$ and $V$ are forced to be equal to actual payoffs $w$ and $v$. But if $\beta^{j}=0$ there are no actual bond payoffs to prevent expectations from becoming absurdly pessimistic. We impose some rationality by forcing households to assume that a small bond issue would indeed fully deliver $W_{s j}=1$ to them in those states where the firm is flush with cash $V_{s j}>0$. (It follows from our shareholder control hypothesis and our hypothesis that firms begin with positive endowments, that there will be such states.)

Existence Theorem: Any monetary economy with positive firm endowments and concave firm utilities, satisfying the shareholder control hypothesis and the derivatives delivery hypothesis, has a monetary equilibrium (in which money has positive value).

The theorem shows that fiat money has value in our finite horizon, incomplete markets economy. Its proof is in the appendix. We proved similar theorems for pure exchange economies in [1992], [2003a], and [2003b], but there we needed to assume that there were sufficient gains to trade at the initial endowments. Here with production we make no such assumption. Money is essential because the firms have no way to deliver anything to their shareholders except by selling goods for money and distributing the money revenue as dividends. The separation of firm ownership from control thus helps to explain why money has value.

The existence theorem holds even though there is almost no impediment or limit to firm defaults. The shareholder control hypothesis ensures that at least in one state firm dividends on the original share must not be less than the value of the firm's initial endowment in that state. Since bonds and bank loans have higher seniority than equity, this guarantees that bank loans and firm bonds completely pay in at least one state, giving them some value. Their prices (i.e. their interest rates) adjust in equilibrium to reflect the potential defaults in the other states.

If we wish to focus on a model without default, we could simply add a constraint to the firm's choices $\sigma^{j}$ prohibiting default. Equivalently, we could simply assume a 
sufficiently harsh penalty for defaulting in the firm utilities $u^{j}$, as we show in Section 5 .

The upshot is that in our general equilibrium model with money and production, equilibrium exists for every monetary policy choice $\left(M_{0}, M_{\overline{0}},\left(M_{s}\right)_{s \in S}\right)$.

Quite robustly the monetary authority will be able to improve the efficiency of trade, and thus total real output, by increasing supplies of bank money, and thus lowering interest rates. This will have the additional side benefit (or cost) of increasing price levels and thus reducing the real wealth of those who begin with high initial stocks of money $m_{s}^{h}>0$. But there is a situation in which the monetary authority will eventually be stymied in its efforts to increase output and the price levels by increasing $M_{0}$. This we call the liquidity trap.

\section{Robust Liquidity Trap}

The liquidity trap is one of the most famous, and most mystifying, monetary phenomena. According to Keynes, the introduction of more money into the system via government monetary policy generally lowers interest rates and stimulates output. But when interest rates get too low, the monetary authority loses its power, and further injections of money fail to move interest rates or prices or any real variables for that matter. Households simply hold larger and larger real money balances in their portfolios.

A number of writers challenged Keynes' story, because he did not adequately explain how it could be that households would hold more and more money in their portfolios without any inducement from changing prices (which are fixed in the liquidity trap). In what follows we show that this phenomenon not only can happen, but always will happen if the government cannot commit to increasing future stocks of bank money when it increases current stocks of bank money.

Our proof that the liquidity trap is inevitable is a simple application of our existence proof. It does not require any special assumptions about utility of consumption. We shall show under the same assumptions used to prove the existence of equilibrium, that as the central bank increases $M_{0}$, holding $M_{\overline{0}}$ and $\left(M_{s}\right)_{s \in S}$ fixed, the short interest rate $r_{0}$ will eventually hit zero while $M_{0}$ is still finite. Further increases in $M_{0}$ will have no effect on prices, but simply induce the private sector to hold larger real money balances. Households will borrow the extra money at zero interest, hoard it in their pockets, and then return it unused at the end of period 0. Furthermore, if there is no default in any equilibrium, then by the time $r_{0}$ is forced down to zero, at least one of (and perhaps all of) $r_{\overline{0}},\left(r_{s}\right)_{s \in S}$ will be forced higher than it was to begin with! Initially, as $M_{0}$ is increased, there will be downward pressure on all interest rates, perhaps even lowering the entire yield curve. Eventually, however, the short end will be forced to zero while the long end will if anything be higher than before.

To see why the liquidity trap is important, recall that a positive money rate of interest has obvious economic disadvantages in our liquidity-constrained world. It drives a wedge between buying and selling prices, and thus prevents full efficiency both in exchange and production. When there is production, interest rates from 
different periods come into play, so that if any one of $r_{0}, r_{\overline{0}},\left(r_{s}\right)_{s \in S}$ is high, production may be curtailed. The firm might have to borrow money at the long interest rate $r_{\overline{0}}$ to buy the inputs at time 0: if the long interest rate is too high, the firm may be discouraged from producing. Similarly, a household selling labor to the firm at time 0 might be discouraged from doing so because in order to use its labor income at time 0 to consume at time 0 it will have to take out a short term loan. If the short interest rate $r_{0}$ is high, the household might be discouraged from selling its labor to the firm, pushing up the price of labor and reducing output of the firm. In the same vein, if the short interest rate in period 1 is high, consumers might be loath to borrow the money needed to buy the firm's output at time 1, reducing demand and therefore reducing the firm's price of output and again reducing production.

Interest rates will generally be high when there is a large amount of outside money $\left(\sum_{t \in H \cup J} m_{s}^{h}\right)_{s \in S^{*}}$ relative to the available inside money $\left(M_{n}\right)_{n \in N}$. Increasing the stocks of bank money thus generally helps to reduce interest rates. But if these stocks are increased in too unbalanced a way, then paradoxical effects like the liquidity trap are bound to crop up. The central bank must act intelligently, and have a reputation for acting intelligently (since it cannot credibly commit to raising bank money tomorrow except through its reputation).

The key insight is that in equilibrium the following monetary inequality must hold

$$
r_{0} M_{0}+r_{\overline{0}} M_{\overline{0}}+r_{s} M_{s} \geq \sum_{t \in H \cup J}\left(m_{0}^{t}+m_{s}^{t}\right) \forall s \in S
$$

(with equality if there is no bankruptcy). This is so because nobody will hold worthless fiat money at the end of any state $s$ in period 1. (Anybody who does could have increased his utility by spending more on goods in state $s$, either by spending idle balances or borrowing more, without violating any budget constraint). Hence across any time path $(0, s)$, all the money $M_{0}+M_{\overline{0}}+M_{s}+\sum_{t \in H \cup J}\left(m_{0}^{t}+m_{s}^{t}\right)$ must be repaid to the banks, and since nobody will repay more than he owes, all of it (at least) must be owed to the banks, either as principal $M_{0}+M_{\overline{0}}+M_{s}$, or as interest payments $r_{0} M_{0}+r_{\overline{0}} M_{\overline{0}}+r_{s} M_{s}$. If there is no default, then exactly what is owed will be repaid, and the monetary inequality becomes an equality.

From our existence theorem, we know that there must be a monetary equilibrium no matter what the values of

$$
(M, m)=\left(M_{0}, M_{\overline{0}},\left(M_{s}\right)_{s \in S}, m_{0}=\sum_{t \in H \cup J} m_{0}^{t},\left(m_{s}=\sum_{t \in H \cup J} m_{s}^{t}\right)_{s \in S}\right) \gg 0 .
$$

So let us begin with $(M, m)$ and an equilibrium in which $r_{0}>0$. Suppose the monetary authority increases $M_{0}$ in order to lower the current short term interest rate $r_{0}$, perhaps also hoping thereby that all interest rates will decline, and production will subsequently be boosted. ${ }^{7}$

\footnotetext{
${ }^{7}$ Our model took the bank stocks $M_{n}$ exogenous, and the interest rates $r_{n}$ endogenous. We could have instead reversed this without disturbing the ME.
} 
But suppose the households and firms refuse to believe that the monetary authority will increase future bank money either via long loans $M_{\overline{0}}$ or future money supplies $\left(M_{s}\right)_{s \in S}$. What will happen?

Eventually the monetary authority will hit a liquidity trap. The reason for this is as follows. Prices at every state $s \in S$ at time 1 are bounded above, independent of $M_{0}$, since the total stock of money available to be spent there is no more than

$$
M_{\overline{0}}+M_{s}+m_{0}+m_{s}
$$

whereas at least the firm endowments

$$
\sum_{j \in J} e_{s}^{j}>0
$$

are put up for sale. If period 1 prices are bounded above, then period 0 prices cannot become too large, for otherwise any household could sell a sliver in period 0 and buy up the whole economy in every state in period 1 . This observation leads us to conclude that for large $M_{0}$, equilibrium $r_{0}=0$, as we now argue.

If $r_{0}>0$, then all of $M_{0}$ must be borrowed (since the loan market 0 clears) and spent in time 0 on something (nobody would borrow money at positive interest unless he was going to spend it). Since payments on firm bonds, firm dividends, and derivatives are each bounded above by the stock of money available in state $s$, the payments by any one of these securities is bounded above, independent of $M_{0}$. Nobody would buy a security for more than the maximum money it delivers across future states, hence there is an upper bound, independent of $M_{0}$, on how much money is being spent on securities at time 0 . The rest must be spent on goods. Since no more than $\sum_{h \in H} e_{0}^{h}$ goods can be put up for sale, prices $p_{0}$ would then become arbitrarily large for all large $M_{0}$, contradicting the boundedness of period 0 prices. Hence, as $M_{0}$ rises, eventually $r_{0}=0$, and the hoarding of real money balances thereafter increases proportionately with $M_{0}$.

The argument just given proves

Liquidity Trap Theorem: Fix $E \backslash M_{0}=\left\langle\left(M_{\overline{0}},\left(M_{s}\right)_{s \in S}\right),\left(u^{h}, e^{h}, m^{h}\right)_{h \in H},\left(u^{j}, e^{j}, m^{j}, Y^{j}\right)_{j \in J}, A\right\rangle$. Then there is a level of bank money $M_{0}^{*}$ at time 0 , and commodity price levels $p_{0}^{*}$, such that for every monetary economy $E=\left(M_{0}, E \backslash M_{0}\right)$ with $M_{0} \geq M_{0}^{*}$ and every monetary equilibrium $\left(\eta,\left(\sigma^{j}\right)_{j \in J}\right)$ for $E, r_{0}=0, p_{0} \leq p_{0}^{*}$, and households horde at least $M_{0}-M_{0}^{*}$ as unspent money balances during period 0.

Note that if we also assumed that no default occurs in equilibrium, then the monetary inequality must be an equality. Once the short rate $r_{0}$ drops to 0 , the monetary equality can be maintained only if some other rate increases.

\section{Motivation of the Firm}

The separation of firm ownership and control guarantees that money has value: firms are forced to sell their goods for money in order to pay their shareholders. These 
sales alone give money value (and encourage other sales for money), provided that the usual concavity hypotheses hold, as we saw in the Existence Theorem.

Unfortunately, this separation of ownership from control makes it problematic to interpret concave utility maximization for the firm. In the case of a single consumer, concave utility maximization is tantamount to assuming rational choices, diminishing marginal utility, and unlimited liability for breaking promises. A special case of our model, which may satisfy the reader, restricts each firm to a single owner who is not allowed to trade shares or to let the firm default. But in reality a firm may have multiple owners, whose negotiated decisions will not likely correspond to the decisions of a single utility maximizer. And the limited liability of the firm gives a payoff to shareholders that is convex instead of concave. These difficulties have been pointed out before. Here we show how far we can go in interpreting the concave maximization framework for the firm. The key idea is that the dependence of $u^{j}$ on the macro variables $\eta$, as well as on the firm choices $\sigma^{j}$, permits us to represent some of these possibilities.

\subsection{The single manager firm with default penalties}

Let us start with the simplest example, in which the firm is managed by one agent, not necessarily a shareholder, who will keep control and will not sell new equity. Simplifying further, suppose his utility is simply a weighted average of money payoffs across the states. Denote by $z_{s}$ the revenue minus debt of the firm in state $s$, i.e., denote the linear revenue function by

$$
z_{s}\left(\eta, \sigma^{j}\right) \equiv p_{s} \cdot\left(\bar{y}_{s}^{j}+e_{s}^{j}\right)-\mu_{\overline{0}}^{j}-\beta^{j} .
$$

Let $\left\{\gamma_{s}\right\}_{s \in S}$ be a probability distribution on states $s \in S$. Then $\gamma_{s}$ will represent the weight put on a dollar of dividends in state $s$. But that still leaves us with the question of how to evaluate money defaults. Let $\lambda_{s} \geq 0$ be a "default penalty rate," so that $\lambda_{s} \gamma_{s}$ represents the utility loss of a dollar default in state $s$. Then we could define

$$
u^{j}\left(\eta, \sigma^{j}\right) \equiv \sum_{s \in S} \gamma_{s}\left(\left(z_{s}\left(\eta, \sigma^{j}\right)\right)^{+}-\lambda_{s}\left(-z_{s}\left(\eta, \sigma^{j}\right)\right)^{+}\right) .
$$

When the firm is controlled by such a manager, and distributing money to its shareholders, it values a marginal dollar by $\gamma_{s}$. When the firm is in default, it values a marginal dollar according to $\lambda_{s} \gamma_{s}$. As long as $\lambda_{s} \geq 1$, this induces a concave utility on the actions $\sigma^{j}$ of the firm. If $\lambda_{s}$ is high enough there will be no default at all.

According to this utility, the manager is balancing a weighted average of the dividends that his shareholders might receive

$$
\sum_{s \in S} \gamma_{s}\left(z_{s}\left(\eta, \sigma^{j}\right)\right)^{+}
$$

against the embarrassment he might personally feel if the firm goes bankrupt

$$
-\sum_{s \in S} \lambda_{s} \gamma_{s}\left(-z_{s}\left(\eta, \sigma^{j}\right)\right)^{+}
$$


So far there is no explanation of where the $\gamma_{s}$ come from. This brings us to the next simplest example satisfying the firm's concave utility hypothesis. Suppose the manager is actually one of the household types $h$, and also a shareholder who cannot sell any of his shares, or issue new shares. There is now reason for him to care directly about the dividends of the firm, since he gets a nonzero share of them. It is wellknown that maximizing a concave function with maximum at a value $y$ is equivalent to maximizing a linear function given by the supporting hyperplane to the concave function at $y$. Therefore we use the marginal utilities of income of the manager as the weights $\gamma$.

More precisely, let $\eta$ be a vector of macro variables, as before. Suppose the $u^{h}$ are strictly concave and smooth. Then for given $\eta$, we can define the (unique) utility maximizing consumption vector $x^{h}(\eta)$ for each agent $h$. Let $\gamma^{h}(\eta) \in \mathbb{R}_{+}^{S}$ be the vector of marginal utilities of an extra dollar given to $h$ in states $s=1, \ldots, S$ at the moment dividends are distributed. (e.g. if agent $h$ is selling $\ell$ in state $s$, and still consuming some $s \ell$,then $\gamma_{s}^{h}(\eta)=\left(1 / p_{s \ell}\right)\left[\partial u^{h}(x) / \partial x_{s \ell}\right]$.) Fix an agent $h$ who controls the firm. Consider the utility given by

$$
u^{j}\left(\eta, \sigma^{j}\right) \equiv \sum_{s \in S} \gamma_{s}^{h}(\eta)\left(\left(z_{s}\left(\eta, \sigma^{j}\right)\right)^{+}-\lambda_{s}^{h}\left(-z_{s}\left(\eta, \sigma^{j}\right)\right)^{+}\right)
$$

For $\lambda_{s}^{h} \geq 1$ this is again concave in $\sigma^{j}$, and for $\lambda^{h}$ large enough, there will be no default.

For $\lambda_{s}^{h}$ large enough to eliminate default, the second term is zero and the manager is effectively maximizing the performance of the firm in terms of the dividends he as an owner (with a fixed share, not necessarily 1 ) is being paid, subject to the constraint that the firm does not default. If $\lambda^{h}$ is lower, so default occurs, then the manager is balancing the dividends he receives as an owner against the embarrassment he incurs as manager for a defaulting enterprise.

\subsubsection{Funding investment}

If the manager were the sole owner, he could directly invest money himself in buying inputs. Let $z_{0}^{j}$ be the money contributed by the owner-manager of firm $j$ towards the purchase of inputs. Let $\gamma_{0}^{h}(\eta) \in \mathbb{R}$ be the marginal utility of an extra dollar to $h$ in state $s=0$ at the moment $h$ would have to buy inputs for the firm. If $h$ is buying good $\ell$ for consumption, then $\gamma_{0}^{h}(\eta)=\left(1 / p_{s \ell}\right) \partial u^{h}(x) / \partial x_{s \ell}$. Then with the default penalties above, the owner-manager $h$ would maximize

$$
u^{j}\left(\eta, \sigma^{j}, z_{0}^{j}\right) \equiv-\gamma_{0}^{h}(\eta) z_{0}^{j}+\sum_{s \in S} \gamma_{s}^{h}(\eta)\left(\left(z_{s}\left(\eta, \sigma^{j}\right)\right)^{+}-\lambda_{s}^{h}\left(-z_{s}\left(\eta, \sigma^{j}\right)\right)^{+}\right)
$$

which is again concave.

Now let the owner-manager contemplate issuing shares to raise additional money for inputs, instead of contributing $z_{0}^{j}$. His utility should then be

$$
u^{j}\left(\eta, \sigma^{j}\right)=\sum_{s \in S} \gamma_{s}^{h}(\eta)\left(\frac{1}{1+f^{j}}\left(z_{s}\left(\eta, \sigma^{j}\right)\right)^{+}-\lambda_{s}^{h}\left(-z_{s}\left(\eta, \sigma^{j}\right)\right)^{+}\right) .
$$


This appears to be a completely different expression, since the cost of issuing shares shows up as a dilution, and not as a direct cost. It is also not concave in $f^{j}$. However, if the default penalties are high enough so that there is no default by the firm, then these two expressions induce the same behavior by the firm, provided that only the owner is allowed to buy the new equity.

The first expression becomes

$$
u^{j}\left(\eta, \sigma^{j}\right) \equiv-\gamma_{0}^{h}(\eta) \rho_{j} f^{j}+\sum_{s \in S} \gamma_{s}^{h}(\eta) z_{s}\left(\eta, \sigma^{j}\right)
$$

which must be maximized subject to the constraint that the firm does not default. The second expression becomes

$$
u^{j}\left(\eta, \sigma^{j}\right) \equiv \sum_{s \in S} \gamma_{s}^{h}(\eta) \frac{1}{1+f^{j}} z_{s}\left(\eta, \sigma^{j}\right)
$$

which again must be maximized subject to no default. If only $h$ is buying the new equity, and there is no default, the first-order conditions for maximization imply

$$
\gamma_{0}^{h}(\eta) \rho_{j}=\sum_{s \in S} \gamma_{s}^{h}(\eta) \frac{1}{1+f^{j}} z_{s}\left(\eta, \sigma^{j}\right)
$$

A change in $f^{j}$ and a corresponding change in the $z_{s}\left(\eta, \sigma^{j}\right)$ increases the second expression if and only if the first expression also increases.

\subsection{Multiple Owners}

Everything we said about a single owner can be extended to multiple owners according to the Dreze criterion [1974] We no longer need worry that the original shareholders remain the final shareholders, or that the same households who buy the original shares also buy the new equity.

Let $\delta_{j}^{h}(\eta) \geq 0$ be the final ownership shares of firm $j$ at $\eta$. Let $\omega_{j}^{h}(\eta)=\delta_{j}^{h}(\eta) / \sum_{i=1}^{H} \delta_{i}^{h}(\eta)$. Now define the goals of firm $j$ by

$$
u^{j}\left(\eta, \sigma^{j}\right) \equiv \sum_{h=1}^{H} \omega_{j}^{h}(\eta)\left\{-\gamma_{0}^{h}(\eta) \rho_{j} f^{j}+\sum_{s \in S} \gamma_{s}^{h}(\eta)\left(\left(z_{s}\left(\eta, \sigma^{j}\right)\right)^{+}-\lambda_{s}^{h}\left(-z_{s}\left(\eta, \sigma^{j}\right)\right)^{+}\right)\right\} .
$$

This is a concave function of the choice variables of the firm, if each $\lambda_{s}^{h} \geq 1$. If the $\lambda_{s}^{h}$ are sufficiently high to choke off all default, then maximizing this criterion is, by the same argument given above, equivalent to maximizing

$$
u^{j}\left(\eta, \sigma^{j}\right) \equiv \sum_{h=1}^{H} \omega_{j}^{h}(\eta) \sum_{s \in S} \gamma_{s}^{h}(\eta) \frac{1}{1+f^{j}} z_{s}\left(\eta, \sigma^{j}\right) .
$$

Dreze [1974] proposed the function $u^{j}$ obtained by setting $\omega^{h}(\eta)=\delta^{h}$. The firm, he argued, ought to act in the interest of the final shareholders.

Grossman-Hart [1979] proposed setting $\omega^{h}(\eta)=\bar{\delta}^{h}$, with the idea in mind that the firm would act in the interest of the original shareholders.

Alternatively, one could consider other arbitrary weighted sums of firms' incomes $\left[p_{s} \cdot\left(\bar{y}_{s}+e_{s}^{j}\right)\right]$ in state $s(s=1, \ldots, S)$, and $-p_{0} \cdot x_{0}^{j}$ in state 0 . 


\subsection{Shameless Default or Limited Liability}

So far we have guaranteed concavity of the utility functions of dividend-driven compensation by assuming that there was some cost or shame in defaulting. If limited liability is taken to heart, so that defaulting is truly cost-free, then there is an essential nonconcavity. We can retain our formalism only by accepting the idea of "local optimization."

Given $\eta$, define $\lambda_{s}(\eta)=1$ if $V_{s}(\eta)>0$, and $\lambda_{s}(\eta)=0$ if $W_{s}(\eta)<1$ and $\lambda_{s}(\eta) \in$ $[0,1]$ if $W_{s}(\eta)=1$ and $V_{s}(\eta)=0$. Define

$$
u^{j}\left(\eta, \sigma^{j}\right) \equiv \sum_{h=1}^{H} \omega_{j}^{h}(\eta)\left\{-\gamma_{0}^{h}(\eta) \rho_{j} f^{j}+\sum_{s \in S} \lambda_{s}(\eta) \gamma_{s}^{h}(\eta) z_{s}\left(\eta, \sigma^{j}\right)\right\} .
$$

If the firm is paying dividends, then the owners value an extra dollar in state $s$ by the entire marginal utility of money $\lambda_{s}(\eta) \gamma_{s}^{h}(\eta)=\gamma_{s}^{h}(\eta)$. If the firm is defaulting then an extra dollar will not matter to dividends, so it is valued at zero, $\lambda_{s}(\eta) \gamma_{s}^{h}(\eta)=0$. If the firm is on the brink of defaulting, then a marginal dollar is valued somewhere in between.

This is again a concave function, and maximizing it is equivalent to maximizing

$$
\sum_{h=1}^{H} \omega_{j}^{h}(\eta) \sum_{s \in S} \lambda_{s}(\eta) \gamma_{s}^{h}(\eta) \frac{1}{1+f^{j}} z_{s}\left(\eta, \sigma^{j}\right)
$$

When the firm is on the brink of default in some state $s$, the weight $\lambda_{s}(\eta)$ is meant to be determined by the monetary equilibrium, not a priori.

But this criterion only makes sense locally. If a firm is defaulting in some state $s$, and discovers a technology that produces money in that state for free, the firm will not use it, since for local changes the extra money will go to bondholders and not to dividends. But for a big increase, the bondholder can be paid off and the extra output will go to shareholders, and that gets lost in this formalism. 


\section{APPENDIX}

Proof of the Existence Theorem It might help to first outline the idea of the proof. For any $\varepsilon>0$, we define a generalized game $\Gamma^{\varepsilon}$ on a continuum player-set with types $T=H \cup J$. Each type $t \in T$, household or firm, corresponds to a continuum of identical players of measure one. There is also an "external player" who is a strategic dummy. He puts up $\varepsilon$ units for sale of every instrument except for derivatives, of which he puts up only $\varepsilon^{2}$; furthermore, he puts up $\varepsilon$ units of money for purchase at every market. He then fully delivers on his bond promises. However, on his $\varepsilon^{2}$ sale of each derivative he delivers only up to a cap of $\varepsilon$ dollars, i.e., he delivers $\min \{$ what he owes, $\varepsilon$ \} in each state $s \in S$. (The external agent is allowed to create money to do all this, just as he creates the instruments he sells.) The other (real) players choose how much of each instrument to sell, and how much money to spend on each instrument, as described in Section 2 before.

At any market, prices form as the ratio of total money spent to the total sales. Thus markets always clear (taking the external player into account), though the real players optimize on their feasible choice sets only at Nash equilibria (NE) of $\Gamma^{\varepsilon}$. A type-symmetric NE of $\Gamma^{\varepsilon}$ will be called an " $\varepsilon$-ME" and a limit of $\varepsilon$-ME, as $\varepsilon \rightarrow 0$, will be shown to be a bona-fide ME.

We now begin the proof formally. Throughout we confine ourselves to typesymmetric choices so that $\sigma^{t}$ will sometimes mean the aggregate action of all players of type $t$, and at other times it will denote the choice of a single (infinitesimal) player of type $t$; the meaning will always be clear from the context.

For any $\varepsilon>0$ and $t \in T$, define $\Sigma_{\varepsilon}^{t} \equiv\left\{\sigma^{t}: 0 \leq \sigma^{t} \leq 1 / \varepsilon\right\} \equiv$ ambient strategy space of an agent of type $t$ (where the vectors $\sigma^{t}$ are as described in Section 2). These spaces are clearly convex and compact. Given choices $\sigma \equiv\left(\sigma^{t}\right)_{t \in T} \in \underset{t \in T}{X} \Sigma_{\varepsilon}^{t}$, define macrovariables $\eta_{\varepsilon}(\sigma) \equiv(r, \rho, \pi, p, \bar{\delta}, \Delta, W, V)$ recursively as follows (note $\sigma^{t}$ refers to 
aggregates here):

$$
\begin{aligned}
\frac{1}{1+r_{n}} & =\frac{\varepsilon+M_{n}+\sum_{h \in H} \tilde{\mu}_{n}^{h}}{\varepsilon+\sum_{t \in H \cup J} \mu_{n}^{t}} \\
\frac{1}{1+r_{j}} & =\frac{\varepsilon+\sum_{h \in H} \tilde{\beta}_{j}^{h}}{\varepsilon+\beta^{j}} \\
\rho_{j} & =\frac{\varepsilon+\sum_{h \in H} \tilde{f}_{j}^{h}}{\varepsilon+f^{j}+\sum_{h \in H} f_{j}^{h}} \\
\pi_{k} & =\frac{\varepsilon+\sum_{h \in H} \tilde{\alpha}_{k}^{h}}{\varepsilon+\sum_{h \in H} \alpha_{k}^{h}} \\
p_{s \ell} & =\frac{\varepsilon+\sum_{t \in H \cup J} \tilde{q}_{s \ell}^{t}}{\varepsilon+\sum_{t \in H \cup J} q_{s \ell}^{t}} \\
\bar{\delta}_{j}^{h} & =\frac{\operatorname{exogenous}}{\tilde{f}_{j}^{h}} \\
\Delta_{j}^{h} & =\bar{\delta}_{j}^{h}-f_{j}^{h} \\
W_{s j} & =\frac{\beta_{j}}{\varepsilon+\beta_{j}} \min \left\{\frac{1}{\beta_{j}}\left[p_{s} \cdot\left(\bar{y}_{s}^{j}+e_{s}^{j}\right)-\mu_{\overline{0}}^{j}\right]^{+}, 1\right\}+\frac{\varepsilon}{\varepsilon+\beta_{j}} \\
V_{s j} & =\left[p_{s} \cdot\left(\bar{y}_{s}^{j}+e_{s}^{j}\right)-\mu_{\overline{0}}^{j}-\beta^{j}\right]^{+} /\left(\varepsilon+1+f^{j}\right)
\end{aligned}
$$

Further define

$$
\begin{aligned}
A_{s k}^{\varepsilon, \sigma}\left(\bar{\eta}_{0}, \bar{\eta}_{s}\right)= & \left(\frac{\varepsilon^{2}}{\varepsilon^{2}+\sum_{h \in H} \alpha_{k}^{h}}\right) \min \left\{A_{s k}\left(\bar{\eta}_{0}, \bar{\eta}_{s}\right), 1 / \varepsilon\right\} \\
& +\left(\frac{\sum_{h \in H} \alpha_{k}^{h}}{\varepsilon^{2}+\sum_{h \in H} \alpha_{k}^{h}}\right) A_{s k}\left(\bar{\eta}_{0}, \bar{\eta}_{s}\right) .
\end{aligned}
$$

This is the effective delivery of a unit of derivative $k$ in state $s$, since the external player reneges on deliveries beyond $\varepsilon$ on his sale of $\varepsilon^{2}$ (putting a cap of $1 / \varepsilon$ on his delivery rate).

The payoff to any player of type $t$ (and here $\sigma^{t}$ denotes the infinitesimal choice, while $\sigma$ denotes the aggregate choice) is given by:

$$
\Pi^{t}\left(\sigma, \sigma^{t}\right)=\left\{\begin{array}{ll}
u^{h}\left(\left(e_{s \ell}^{h}-q_{s \ell}^{h}+\frac{\tilde{q}_{s \ell}^{h}}{p_{s \ell}}\right)_{s \ell \in S^{*} L}\right) & \text { if } t \equiv h \in H \\
u^{j}\left(\eta_{\varepsilon}(\sigma), \sigma^{j}\right) & \text { if } t \equiv j \in J
\end{array} .\right.
$$


Finally the subset of $\Sigma_{\varepsilon}^{t}$ that is feasible for (infinitesimal) $t$, given aggregate choices $\sigma$ by the continuum, is

$$
\tilde{\Sigma}_{\eta_{\varepsilon}(\sigma)}^{t} \cap \Sigma_{\varepsilon}^{t}
$$

where $\tilde{\Sigma}_{\eta_{\varepsilon}(\sigma)}^{t}$ is defined in exactly the same manner as $\Sigma_{\eta_{\varepsilon}(\sigma)}^{t}$, but replacing $A_{s k}\left(\bar{\eta}_{0}, \bar{\eta}_{s}\right)$ with $A_{s k}^{\varepsilon, \sigma}\left(\bar{\eta}_{0}, \bar{\eta}_{s}\right)$ for all $s, k$. This completes the description of the generalized game $\Gamma^{\varepsilon}$. Since all the standard convexity/concavity and continuity assumptions are clearly satisfied, we have

Step 1. An $\varepsilon$-ME (i.e., type-symmetric NE of $\Gamma^{\varepsilon}$ ) exists for every $\varepsilon>0$.

In the steps below, we examine, a sequence $\left(\eta_{\varepsilon}(\sigma(\varepsilon)), \sigma(\varepsilon)\right)$ of $\varepsilon-M E$ as $\varepsilon \rightarrow 0 .^{8}$ (For notional simplicity, we suppress $\varepsilon$ in $\sigma(\varepsilon)$.)

Step 2. $\mu_{n}^{t}, \beta^{j}$ are bounded above (and, thus, so are the $r_{n}$ for $n \in N$ ).

Proof. Notice that the external player creates $\varepsilon$ units of commodities and $\varepsilon$ units of money at finitely many markets, and further creates at most $(J+K) \varepsilon$ more units of money to deliver on his sale of the $J$ bonds and the $K$ derivatives. So the total amount of money or commodities at any juncture is bounded by some constant $D$ for all small enough $\varepsilon$ (recalling condition (iii) on $Y^{j}$, which bounds production). Thus $\mu_{n}^{h} \leq D$ for $h \in H$, otherwise $h$ cannot repay loan $n$ (at the $\varepsilon$-ME under consideration). Next, if $\mu_{\overline{0}}^{j}>D$ for any $j$, then $j$ will go bankrupt in every state $s \in S$, so that $v_{s j}=0$ for all $s \in S$; but clearly $p_{s \ell}>0$ on account of the external $\varepsilon$-player, so $p_{s} \cdot e_{s}^{j}>0$ for all $s \in S$, contradicting the shareholder control hypothesis (SCH). We conclude that $\mu_{\overline{0}}^{j} \leq D$ for all $j \in J$; and, for the same reason, $\beta^{j} \leq D$ for all $j \in J$.

Step 3. All $r_{n} \geq 0$.

Proof. If some $r_{n}<0$, a household can borrow $\phi$ more of money on loan $n$ for small enough $\phi$ and $\epsilon$ (since by step $2, \mu_{n}^{h}<1 / \varepsilon$ for small $\varepsilon$ ), return $\left(1+r_{n}\right) \phi$ and have $-r_{n} \phi>0$ money left over for purchasing commodities, contradicting that he has maximized.

Step 4. Commodity prices $p_{s \ell}$ are bounded away from 0 .

Proof. Suppose $p_{s \ell} \longrightarrow 0$ as $\varepsilon \rightarrow 0$ for some $s \ell$. Then a household $h$ with $m_{0}^{h}>0$ can buy arbitrarily large amounts of $s \ell$ with his $m_{o}^{h}$ (inventorying the money into period 1 if $s \in S)$, obtaining utility more $\operatorname{than}^{9} u^{h}(D, \ldots, D)$, contradicting that $\sigma^{h}$ has maximized $u^{h}$ on $\tilde{\Sigma}_{\eta_{\varepsilon}(\sigma)}^{h} \cap \Sigma_{\varepsilon}^{h}$.

Step 5. Commodity prices $p_{s \ell}$ are bounded from above.

\footnotetext{
${ }^{8}$ Here the first $\sigma(\varepsilon)$ denotes aggregate choices and the second $\sigma(\varepsilon)$ denotes individual choices! (We shall, from now on, stop tracking the difference, which will be clear from the context.)

${ }^{9}$ To see this, note that - since $u^{h}$ is concave - we may replace it by $\tilde{u}^{h}(x) \equiv$ $\min \left\{u^{h}(x),\left\{H_{y}(x)\right\}_{y \in \square}\right\}$, where $H_{y}: \mathbb{R}^{S^{*} L} \rightarrow \mathbb{R}$ is the supporting hyperplane to $u^{h}$ at $y$ and $\square$ is the cube $\left\{z \in \mathbb{R}_{+}^{S^{*} L}:\|z\| \leq D\right\}$. Then $u^{h}=\tilde{u}^{h}$ on $\square$ and $\varepsilon$-ME are unaffected if we replace $u^{h}$ by $\tilde{u}^{h}$. But $\tilde{u}^{h}\left(0, \ldots, 0, z_{s \ell}, 0, \ldots, 0\right) \rightarrow \infty$ as $z_{s \ell} \rightarrow \infty$.
} 
Proof. First suppose $s \in S$ and some $p_{s \ell} \longrightarrow \infty$ as $\varepsilon \rightarrow 0$ Take $k \in L$ such that $e_{s k}^{j}>0$ for some $j \in J$ ( such a $k$ exists since $e_{s}^{j} \neq 0$ for all $s, j$ ). Then $q_{s k}^{j} \geq e_{s k}^{j}$ since $j$ sells all the goods at hand in period 1 . But the money in the system is bounded by $D$ (see proof of step 1 ). It follows that $p_{s k}$ is bounded above as $\varepsilon \rightarrow 0$.

Consider a household $h$ with final consumption $x_{s \ell}^{h}>0$. Let him cut back $x_{s \ell}^{h}$ by $\omega$ (either by buying less or selling more of $s \ell$ ), releasing at least $\omega p_{s \ell}$ money after commodity trade in state $s$. Against this let him borrow $\omega p_{s \ell} /\left(1+r_{s}\right)$ more on $M_{s}$ (which is feasible for small enough $\varepsilon$ and $\omega$ since, by step $2, \mu_{s}^{h}$ is bounded above while the constraint of $1 / \varepsilon$ on his actions is going to infinity) and use the extra borrowed money to buy $\omega p_{s \ell} /\left(1+r_{s}\right) p_{s k}$ units of $s k$. Since $r_{s}$ is bounded above by Step 2, and $p_{s \ell} / p_{s k} \rightarrow \infty$ as $\varepsilon \rightarrow 0$, it follows that $h$ can improve his payoff, a contradiction. Thus all prices are bounded above in period 1 .

If any price $p_{0 \ell} \rightarrow \infty$, then a household $h \in H$ with $e_{0 \ell}^{h}>0$ can buy an arbitrarily large amount $p_{0 \ell} e_{0 \ell}^{h} / p_{s k}$ of any $s k$ in period 1 (by selling $e_{0 \ell}^{h}$ and inventorying money into period 1), thus obtaining more utility than $u^{h}(D, \ldots, D)$, a contradiction.

Step 6. For each firm $j$, there is some state $s$ such that $v_{s j} \geq p_{s} \cdot e_{s}^{j}$.

Proof. Otherwise, by the shareholder control hypothesis (SCH), $j$ would do better to choose $\sigma^{j}=0$ and simply earn (using Step 4) $p_{s} \cdot e_{s}^{j}$ in each state $s$.

Step 7. All $r_{j}$ are bounded above for bonds.

Proof. Suppose $r_{j} \rightarrow \infty$ as $\varepsilon \rightarrow 0$ for some bond $j$. Then a household $h$ with $m_{0}^{h}>0$ can lend $m_{0}^{h}$ to firm $j$ and receive (by Step 6, according to which $j$ is fully redeeming all its debts in some $s \in S)\left(1+r_{j}\right) m_{0}^{h} \rightarrow \infty$ in some state $s \in S$. Since commodity prices are bounded above (by Step 5 ), he can consume arbitrarily large amounts of goods in state $s$, obtaining utility exceeding $u^{h}(D, \ldots, D)$, a contradiction.

Step 8. All $f^{j}$ are bounded above.

Proof. Suppose some $f^{j} \rightarrow \infty$. Then since $p_{s} \cdot\left(\bar{y}_{s}+e_{s}^{j}\right) \leq D$ for each $s \in S$ (see proof of Step 2), we have $v_{s j} \rightarrow 0$ as $\varepsilon \rightarrow 0$ for all $s \in S$. But $p_{s} \cdot e_{s}^{j}$ is bounded away from 0 (by Step 4 and the assumption that $e_{s}^{j} \neq 0$ for all $s \in S$ and $j \in J$ ). Hence $v_{s j}<p_{s} \cdot e_{s}^{j}$ for all $s \in S$ for small enough $\varepsilon$. Then SCH implies that $j$ would do better to choose $\sigma^{j}=0$, a contradiction.

Step 9. $\rho_{j}$ is bounded away from 0 , and bounded above.

Proof. Suppose some $\rho_{j} \longrightarrow 0$. Let $h$ with $m_{0}^{h}>0$ buy $m_{0}^{h} / \rho_{j}$ shares of firm $j$. Then $h$ will receive (see Step 6) at least $\left(m_{0}^{h} / \rho_{j}\right)\left(p_{s} \cdot e_{s}^{j}\right)$ units of money in some state $s$, which goes to $\infty$ since, by Step 4, $p_{s}$ is bounded away from 0 . But also (Steps 2,5) $p_{s}$ and $r_{s}$ are both bounded above, so $h$ can borrow hugely on $M_{s}$ (anticipating the forthcoming dividends of firm $j$ ) and consume arbitrarily large amounts of commodities in state $s$, obtaining utility above $u^{h}(D, \ldots, D)$, a contradiction.

On the other hand if $\rho_{j} \rightarrow \infty$, any $h$ with $\bar{\delta}_{j}^{h}>0$ can sell $\bar{\delta}_{j}^{h}$ to obtain $\rho_{j} \bar{\delta}_{j}^{h}$ units of money, and inventory it into states $s \in S$ to consume $\rho_{j} \bar{\delta}_{j}^{h} / p_{s \ell}$ of commodities $s \ell$. 
Since the $p_{s \ell}$ are bounded above, he can consume arbitrarily high amounts obtaining utility above $u^{h}(D, \ldots, D)$, again a contradiction.

Step 10. $\left(1 /\left(1+r_{\overline{0}}\right)\right) \min _{s \in S} v_{s j} \leq \rho_{j} \leq \max _{s \in S} v_{s j}$, for sufficiently small $\varepsilon$.

Proof. Suppose $L H S>\rho_{j}$. Then let $h$ borrow $\phi$ more on $M_{\overline{0}}$ (which by Step 2 is feasible for small $\varepsilon$ ) and buy $\phi / \rho_{j}$ more shares of $j$. This will give him $\left(\phi / \rho_{j}\right) v_{s j}>$ $\phi\left(1+r_{\overline{0}}\right)$ by way of dividend in each state, enabling $h$ to return the extra loan, and have money left over for consumption, a contradiction.

Next suppose $\rho_{j}>R H S$. Then $\tilde{f}_{j}^{h}=0$ for all $h \in H$, or else $h$ would do better to inventory the money than spend it on buying shares of $j$. Also $f_{j}^{h}=\bar{\delta}_{j}^{h}$ for essentially the same reason: if $f_{j}^{h}<\bar{\delta}_{j}^{h}$, let $h$ sell $\omega$ more of the shares, and inventory the sales revenue $\omega \rho_{j}$ into every state $s$, losing $\omega v_{s j}$ by way of dividend, but gaining $\omega \rho_{j}$ which is strictly more for all $s \in S$. But then $\rho_{j}=\varepsilon /\left(\varepsilon+1+f^{j}\right) \rightarrow 0$ as $\varepsilon \rightarrow 0$, contradicting Step 9.

Step 11. $A_{s k}^{\varepsilon, \sigma}\left(\bar{\eta}_{0}, \bar{\eta}_{s}\right)=A_{s k}\left(\bar{\eta}_{0}, \bar{\eta}_{s}\right)$ for sufficiently small $\varepsilon$.

Proof. By the above steps, and in conjunction with the obvious facts that $V_{s j} \leq D$ and $W_{s j} \leq 1$, we see that $\bar{\eta}_{0},\left(\bar{\eta}_{s}\right)_{s \in S}$, lie in a compact set as $\varepsilon \rightarrow 0$. Since $A_{s k}\left(\bar{\eta}_{0}, \bar{\eta}_{s}\right)$ is continuous, there exists $\bar{A}$ such that $A_{s k}\left(\bar{\eta}_{0}, \bar{\eta}_{s}\right) \leq \bar{A}$ for all small $\varepsilon$. But $\varepsilon^{2} \bar{A}<\varepsilon$ for small $\varepsilon$, hence $\min \left\{A_{s k}\left(\bar{\eta}_{0}, \bar{\eta}_{s}\right), 1 / \varepsilon\right\}=A_{s k}\left(\bar{\eta}_{0}, \bar{\eta}_{s}\right)$ for small $\varepsilon$, which proves Step 11.

Step 12. $\pi_{k}$ are bounded away from 0 .

Proof. By Steps 3, 4, 9, 10 we have $\bar{\eta} \in \Omega$ for small enough $\varepsilon$. So, by our hypothesis (DDH) on derivative deliveries and by Steps 4 and 9 , it follows that a unit of each derivative $k$ delivers at least $C$ dollars (for some $C>0$ and all small $\varepsilon$ ) in at least one state $s \in S$. Suppose $\pi_{k} \rightarrow 0$ for some $k$. Any $h$ with $m_{0}^{h}>0$ could buy $m_{0}^{h} / \pi_{k}$ of $k$ and obtain $\left(m_{0}^{h} / \pi_{k}\right) C$ dollars in state $s$. Against this, he could borrow $\left(\left(m_{0}^{h} / \pi_{k}\right) C\right) /\left(1+r_{s}\right) \rightarrow \infty$ on $M_{s}$ (recalling that $r_{s}$ is bounded from Step 2) and consume arbitrarily large amounts of goods $s \ell$ at bounded (see Step 5) prices $p_{s \ell}$, obtaining more than $u^{h}(D, \ldots, D)$, a contradiction. Thus $\pi_{k}$ is bounded away from 0 .

Step 13. $\alpha_{k}^{h}$ is bounded above.

Proof. If $\alpha_{k}^{h} \rightarrow \infty$, then $\pi_{k} \rightarrow 0$ since (see proof of Step 2) the expenditure on $k$ is bounded above by $D$. This contradicts Step 12 .

Step 14. $\pi_{k}$ are bounded above.

Proof. Suppose some $\pi_{k} \rightarrow \infty$. By Step 13, the bound of $1 / \varepsilon$ is not binding on derivative sales for small $\varepsilon$. Let any $h$ sell $\omega$ more of $k$ to obtain (and inventory) $\omega \pi_{k}$ dollars. Anticipating this revenue, let him borrow $\omega \pi_{k} / 2\left(1+r_{\overline{0}}\right) \rightarrow \infty$ on $M_{\overline{0}}$ and consume arbitrarily large amounts of 0-period goods at the bounded prices $p_{0}$, obtaining utility above $u^{h}(D, \ldots, D)$. To complete the contradiction, we must show that he can deliver on his sale of $\omega$ and repay the incremental loan on $M_{\overline{0}}$. Clearly half the revenue (i.e., $\omega \pi_{k} / 2$ ) from his sale of $k$ repays the bank loan. But, as shown 
in the proof of Step 11, only $\omega \bar{A}$ is due (at most) on derivative deliveries in any state (for small $\varepsilon$ ). This is more than covered by the other half, since $\pi_{k} \rightarrow \infty$.

Step 15. $\sigma^{t}$ maximizes $u^{t}$ on $\Sigma_{\eta(\varepsilon)}^{t}$, not just on $\tilde{\Sigma}_{\eta(\varepsilon)}^{t} \cap \Sigma_{\varepsilon}^{t}$.

Proof. By Step 11, $\tilde{\Sigma}_{\eta(\varepsilon)}^{t}=\Sigma_{\eta(\varepsilon)}^{t}$ for small $\varepsilon$. But, since the upper bound of $1 / \varepsilon$ is not binding on any component of $\sigma^{t}$ by the preceding steps, and since $u^{t}$ is concave in $\sigma^{t}$, the step immediately follows.

Step 16. Choose a convergent subsequence of $\varepsilon$-ME: $\left(\eta_{\varepsilon}(\sigma(\varepsilon)), \sigma(\varepsilon)\right) \rightarrow(\eta, \sigma)$. Then $(\eta, \sigma)$ is an ME.

Proof. This is obvious in the light of our preceding steps. 


\section{References}

Clower, R.W., 1965. "The Keynesian Counterrevolution: A Theoretical Appraisal." In F.H. Hahn and F.P.R. Brechling, eds., The Theory of Interest Rates. Macmillan.

Dreze, J., 1974. "Investment under Private Ownership: Optimality, Equilibrium and Stability." In J. Dreze, ed., Allocation under Uncertainty: Equilibrium and Optimality. Macmillan, London

Dubey, P., and J. Geanakoplos, 1992. "The Value of Money in a Finite Horizon Economy: A Role for Banks." In P. Dasgupta, D. Gale, O. Hart and E. Maskin, eds., Economic Analysis of Markets and Games. MIT Press, Cambridge..

2003a. "Inside and Outside Money, Gains to Trade, and IS-LM," Economic Theory 21: 347-397.

2003b. "Monetary Equilibrium with Missing Markets," Journal of Mathematical Economics 39: 585-618.

2006. "Determinacy with Nominal Assets and Outside Money," Economic Theory 27(1): 79-106.

Grandmont, J.M., 1983. Money and Value. Cambridge University Press.

Grandmont, J.M., and G. Laroque, 1975. "On Money and Banking," Review of Economic Studies 207-236.

1976. "The Liquidity Trap," Econometrica 44: 129-135.

Grandmont, J.M., and Y. Younes, 1972. "On the Role of Money and the Existence of a Monetary Equilibrium," Review of Economic Studies 39: 355-372.

1973. "On the Efficiency of a Monetary Equilibrium," Review of Economic Studies 40: 149-165.

Grossman, S., and O. Hart, 1979. "A Theory of Competitive Equilibrium in Stock Market Economics," Econometrica 47: 293-329.

Hahn, F.H., 1965. "On Some Problems of Proving the Existence of an Equilibrium in a Monetary Economy." In F.M. Hahn and F.P.R. Brechling, eds., The Theory of Interest Rates. Macmillan, London.

Hool, R.B., 1976. "Money, Expectations and the Existence of a Temporary Equilibrium," Review of Economic Studies 43: 439-445.

Krugman, Paul R., 1998. "It's Baaack: Japan's Slump and the Return of the Liquidity Trap," Brookings Papers on Economic Activity, 2:137-187.

Lucas, R.E., 1980. "Equilibrium in a Pure Currency Economy," Economic Inquiry 18(2): 203-220. 
Lucas, R.E., and N.L. Stokey, 1987. "Money and Rates of Interest in a Cash-inAdvance Economy," Econometrica 55, 491-513.

Tobin, J., 1961. "Money, Capital and Other Stores of Value," American Economic Review (Papers and Proceedings) 51: 26-37.

Tobin, J., 1980. Asset Accumulation and Economic Activity: Reflections on Contemporary Macroeconomic Theory. Yrjö Jahnsson Lectures. University of Chicago Press, Chicago. 